\title{
Edcamp Design for Learning Series: A New Bridge Between Research and Professional Learning
}

Sierra Noakes, Allison Modica, and Kristyn Palazzolo

February 2022

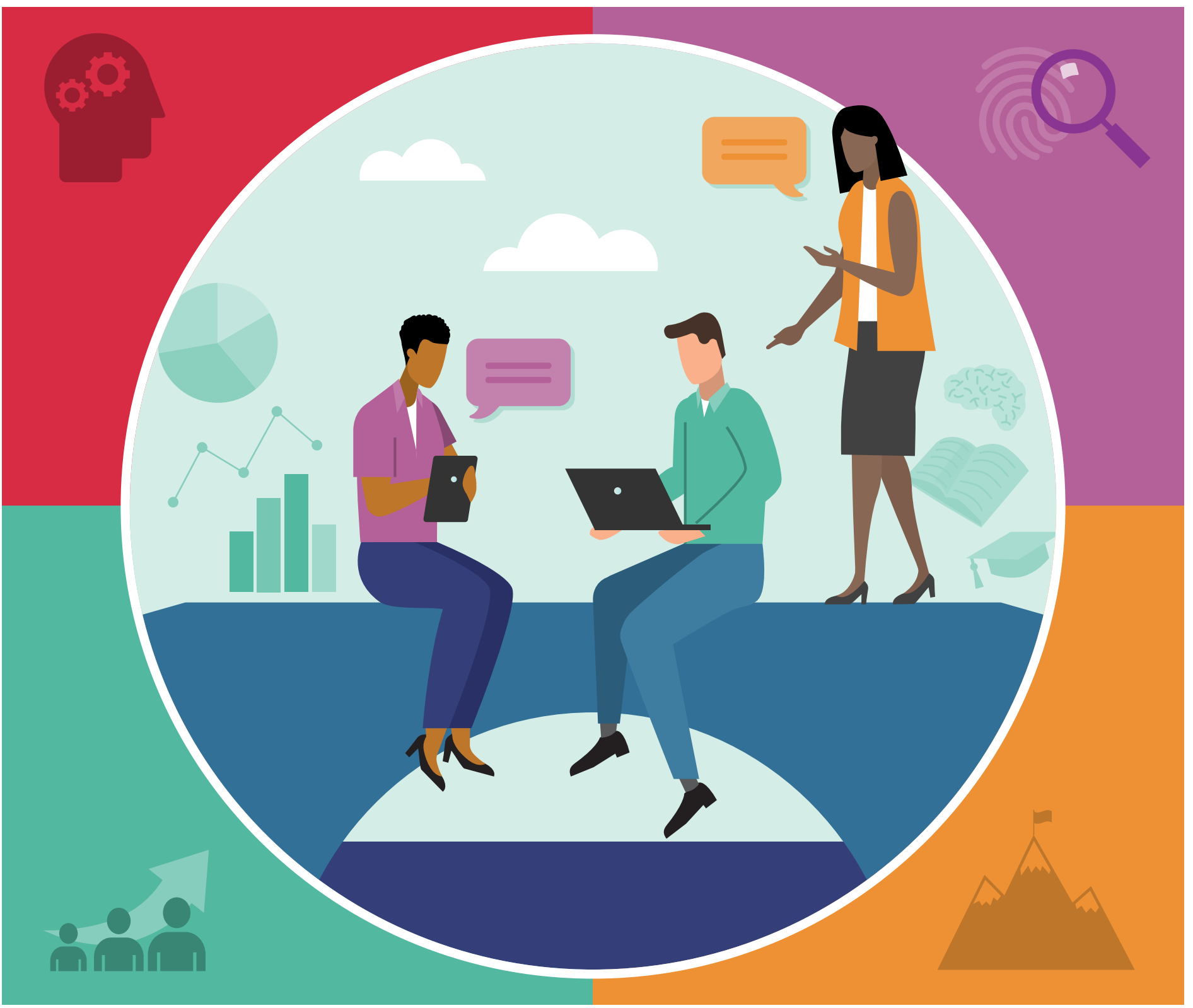

Digital 


\section{Table of Contents}

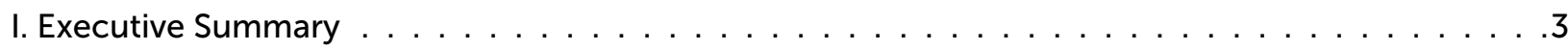

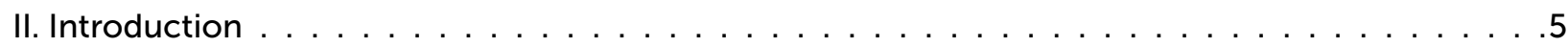

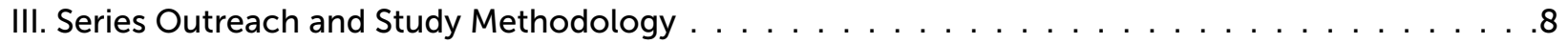

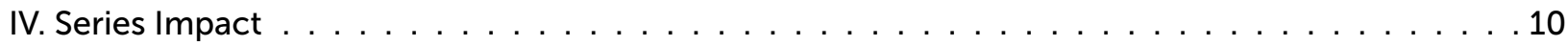

Building a Bridge Between Research and Practice That Centers the Learner . . . . . . . . . . . 18

Appendix A: Individual Variability. . . . . . . . . . . . . . . . . . . . . . . . 19

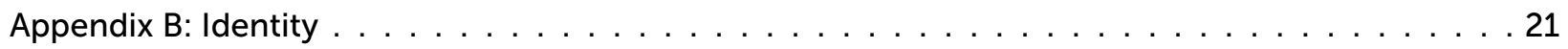

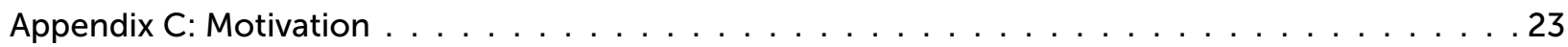

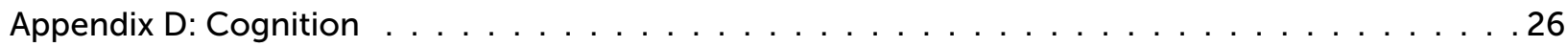

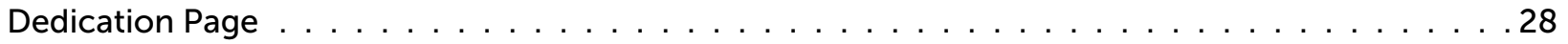

This project has been made possible in part by a grant from the Chan Zuckerberg Initiative DAF, an advised fund of Silicon Valley Community Foundation.

\section{Suggested Citation}

Noakes, S., Modica, A., \& Palazzolo, K. (2022, February). Edcamp design for learning series: A new bridge between research and professional learning. Digital Promise.

https://doi.org/10.51388/20.500.12265/149 


\section{Executive Summary}

As the COVID-19 pandemic shook the education system, teachers were expected to continue teaching without clear direction and support. Never before had the system faced the challenge of universal remote learning. Teachers and students scrambled to secure the technology, structure, and internal motivation required to benefit from learning outside of the classroom. News reports from around the world highlighted educator stories about the challenges of meeting the needs of learners in a highly unpredictable environment.

In response to educators' emerging needs, the Edcamp Community by Digital Promise recognized that teachers needed a unique platform to help them share new insights and practices for teaching remotely. Enhancing its well-established, participant-driven model for teachers by teachers, the Edcamp team partnered with Transcend and Chan Zuckerberg Initiative to develop a series of online Edcamps infusing learning sciences principles centered on Transcend's Designing for Learning framework to help educators better understand how learning happens and how to apply this knowledge to learning design. The series combined insights from research with the Edcamp model and invited educators into the co-design process to create spaces for educators to learn relevant, immediate, and essential skills while connecting with one another to surface challenges and share insights into what is working for their learners.

"This experience opens the doors

to resources, other educators,

and more knowledge to make a

difference."

- Educator Participant
The well-received Edcamp: Design for Learning

(DfL) series successfully built engaging online learning opportunities for educators to learn about research-based approaches to classroom design and instruction. Educators had access to four online research-in-practice Edcamp events centered around the Designing for Learning principles of individual

variability, identity, motivation, and cognition. This unique and innovative professional learning series also generated connections among educators and empowered them to drive their ongoing professional learning to find new strategies to support their learners. Educators left the series with relevant, practical applications to integrate into their practice right away and shared enthusiasm about the experience throughout their surveys and, in some instances, called for more sessions using this format. 
Through participation in the series, three main findings emerged in the data:

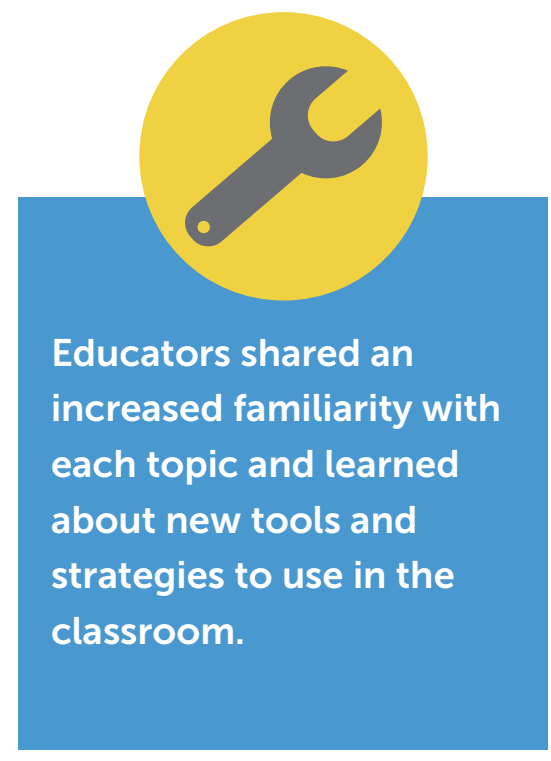

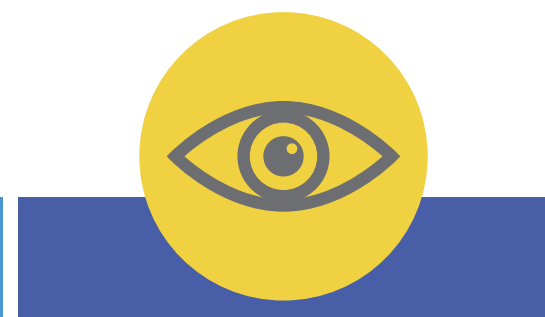

Participants left the series with a renewed focus on building relationships with students and community.

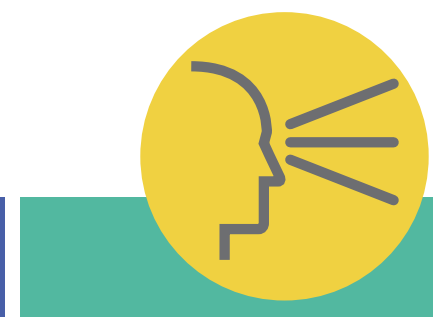

For teachers who

volunteered as panelists and moderators, this new professional learning model supported them to assume new and valuable leadership roles.
"[This Edcamp] really encouraged me to look into metacognition more and gave me techniques as a starting point both for classroom practice and research."

- Educator Participant
In this new era of education, we recognize that educators are looking for easy and meaningful ways to connect, share relevant hands-on strategies, and develop new skills for meeting the needs of their learners. We believe this new research-in-practice Edcamp format provides educators valuable, participant-driven, and research-aligned learning opportunities. We will continue to provide opportunities

for educators to co-create their learning and demonstrate leadership through the model and core tenets of Edcamp. Through our ongoing outreach and support, we will encourage educators to share their learning using this format to organize and host Edcamps for their communities of practice in their schools, districts, and regions.

"I think it will foster more participation from students, and it will give me an opportunity as an educator to build a relationship and make a connection with them. I will be able to use some of their interests to foster a connection with learning new material."

- Educator Participant 


\section{Introduction}

In the face of a worldwide pandemic, educators rose to the challenge of engaging students and families remotely to not only continue learning, but also to provide as much normalcy as possible at a time of chaos and uncertainty. Educators were recognized for their magnanimous efforts to pivot their learning environments and maintain relationships with their learners. However, as additional responsibilities and challenges piled up, educators were not provided the supports (e.g. technical support, social service staff, etc.) necessary to prevent burnout. As a result, many educators used their social media platforms to vent frustrations, find support, and share best practices. As stories of heroes were displayed to the public, many educators were unraveling behind the scenes and looking for quick, meaningful ways to learn new skills to effectively teach remotely and connect with learners from afar. The Edcamp Community by Digital Promise saw this as an opportunity to further demonstrate how the Edcamp model of professional learning paired with learning science research could quickly meet the needs of educators and create spaces for shared learning and networking.

\section{What is Edcamp?}

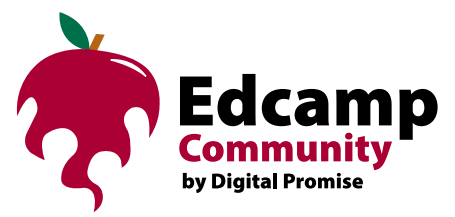

Edcamp is an "un-conference" model of professional development created by teachers for teachers. The model is built on the idea that teachers can learn from and inspire one another to enhance their professional skills with the goal of improving student outcomes. Organized by teacher volunteers, Edcamps are participatory professional development events where educators lead their learning and professional networking through collaboration and shared experiences, rather than traditional sit-and-get professional development presentations. Research from the Bill \& Melinda Gates Foundation confirms that teachers who choose all or most of their professional learning opportunities are more than twice as satisfied with professional development as those with fewer options.

For more than a decade, hundreds of thousands of educators have participated in Edcamps around the world because they are invaluable to participants, as well as cost-effective, scalable, easily replicable, and productive. Edcamps bring educators together to collaboratively build session boards with topics submitted by participants in the room. Educators submit topics of interest, which are then collated to surface the topics of consensus. Once the session board is built, educators then decide which breakout rooms they would like to participate in, learning new information and/or skills from educators sharing their personal experiences. Each breakout room assigns a notetaker who documents key points of discussion, references identified resources, and provides shared contact information in a public note repository (e.g. Padlet) accessible to all participants.

Edcamp's participant-driven model and organic and growing community of teachers demonstrate an essential alternative and supplement to traditional professional development offerings. In post-Edcamp surveys, participants report a unique energy at Edcamp that is part of its power and appeal to teachers. All participants who show up can trust that they will be treated as professionals who have something valuable to contribute to the conversation - from pre-service teachers learning many new skills to veteran educators who have wrestled with persistent challenges for decades. 
The Edcamp Community by Digital Promise understands that teacher-to-teacher learning is not only an effective way to improve practice in the classroom, but also is a crucial strategy to increase teacher satisfaction, develop teacher leaders, and build professional networks. We know that the knowledge, skills, and energy of the classroom teacher are critical factors in student achievement and success. Teachers, administrators, and scholars alike understand the need for educators to continually learn and develop their practice-starting with their teacher preparation and pre-service experiences, and continuing with their initial years of teaching and throughout their careers. Edcamp events result in engaged, empowered, and prepared teachers who adopt effective methods in their classrooms and become leaders and change agents in their schools.

\section{Edcamp Moves Online to Meet the Emerging Needs of Educators}

As the COVID-19 pandemic forced school closures, educators had to figure out how to provide continued learning for students remotely. In addition to the challenges that came with no longer having the structure of a classroom setting and face-to-face interactions with students and colleagues, teachers also had to rely much more on technology to engage students and provide remote classroom learning. For some teachers, this transition was manageable because of their prior experiences teaching with technology. However, many teachers struggled with learning new technology tools, engaging students remotely, collaborating with overwhelmed parents, maintaining professional learning networks, and addressing issues of equity and access for their students.

To quickly meet the emerging needs of educators and demonstrate that best practices can spread more quickly if teachers have opportunities to share them with each other, the Edcamp Community by Digital Promise piloted an initial series of online Edcamps from April-June 2020, collectively titled "Edcamp: Powerful Learning at Home." To maintain its participant-driven model and collectively build session boards, educators were invited to propose topics of discussion during registration that were most meaningful to their immediate teaching needs. The topics resonating most with educators included powerful learning at home, self-care, use of tools and technology, equity, and social-emotional learning. From this series, the Edcamp team identified a much-needed interest in educators better learning how to connect with their students in a remote learning environment. The response was overwhelmingly positive. An average of 300 teachers from around the world registered for each online Edcamp. While in-person Edcamps are specific to regions and districts, online Edcamps provide a unique experience for educators to collaborate despite geographic location. More Edcamp organizers from the community followed suit, hosting online Edcamps to support the ever-evolving needs of educators serving on the frontline of solving the new challenges of remote learning.

\section{Edcamp: Design for Learning (DfL) Series}

Given the success of the online Edcamp: Powerful Learning at Home series and ongoing educator requests for additional Edcamp opportunities, the Edcamp team created the Edcamp: Design for Learning (DfL) series. Supported by the Chan Zuckerberg Initiative and in partnership with Transcend, a national nonprofit organization focused on innovation in school design, we refined our model for online Edcamps to emphasize bringing together learning sciences expertise within Digital Promise and educator context and pedagogy expertise from the Edcamp Community to co-design a series of four online Edcamps. Using Transcend's Designing for Learning framework, the series focused on the principles of individual variability, identity, motivation, and cognition. 
The series included educators in the co-design process from beginning to end, providing opportunities for educators to share their knowledge and experience with peers, demonstrate leadership skills, and inspire others through their stories. During registration, educators were invited to submit topics for the session board and asked if they were interested in volunteering as a panelist and/or breakout session moderator. Selected volunteers were invited to attend

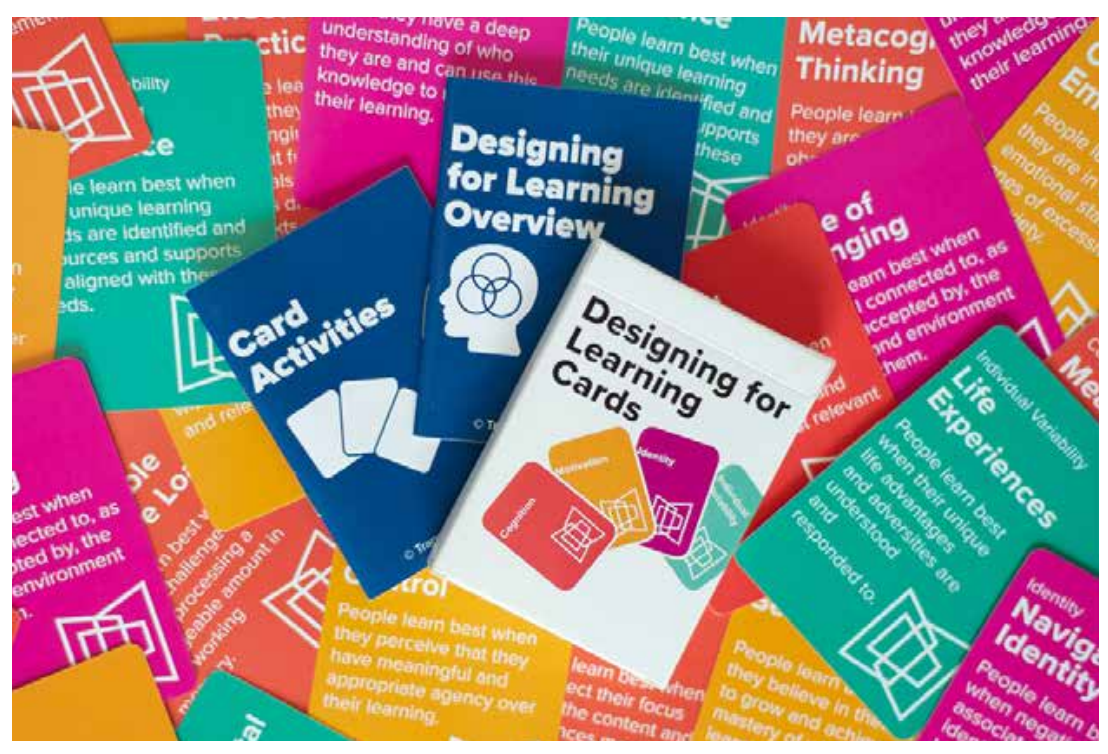
a background building session with a content expert and encouraged to provide input on the discussion content related to Transcend's Designing for Learning Primer and cards. Moderators also were provided techniques for moderating breakout sessions and given time to explore useful resources pertaining to the topics they were encouraged to share at the Edcamp. Inviting educators into the co-design process further promoted the Edcamp model's position of giving teachers voice and choice in their professional learning to increase teacher satisfaction, develop teacher leadership and advance professional recognition.

Each Edcamp began with an educator panel discussion about one of four DfL principles and its relation to classroom design and instruction. Throughout the panel discussion, participants were invited to add top-ofmind topics to the session board as they gained additional insight and information. Following the educator panel discussion and finalization of the session board, consensus topics were used to create breakout rooms. Participants were given autonomy to choose topics of interest and encouraged to navigate in and out of two 45-minute Edcamp sessions with up to 10 breakout rooms. Each breakout room assigned a notetaker to document key points of discussion, reference identified resources, and provide shared contact information in a public note repository (eg. Padlet) accessible to all participants. Following the breakout sessions, all participants were invited to share their learning and networking experiences in a virtual large group format because we believe that bringing the larger group back together provides space to connect and highlight key takeaways documented in session notes. In true Edcamp form, re-grouping for a share out not only reflected the energy and enthusiasm created during breakout sessions, but promoted additional networking opportunities as well.

Across the board, Edcamp participants reported great value in the learning and networking opportunities this series provided. Moderators and panelists shared positive experiences from the opportunity to demonstrate leadership skills with peer educators. We hope this case study provides additional clarity on the role and impact research-in-practice Edcamps have on educators with diverse levels of experience and serves as a platform for continued reflection, learning, and improvement. 
To learn more about the educators participating in these Edcamps and their experiences, we asked participants to complete pre- and post-surveys to provide feedback on the co-design process, perceptions of educator behavior changes, and intentions for replicating in their local professional learning communities. Drawing from educator feedback, this case study shows how this teacher-centered, research-in-practice Edcamp model can lead to positive changes in understanding and practice for teachers. Throughout the series, five major themes emerged
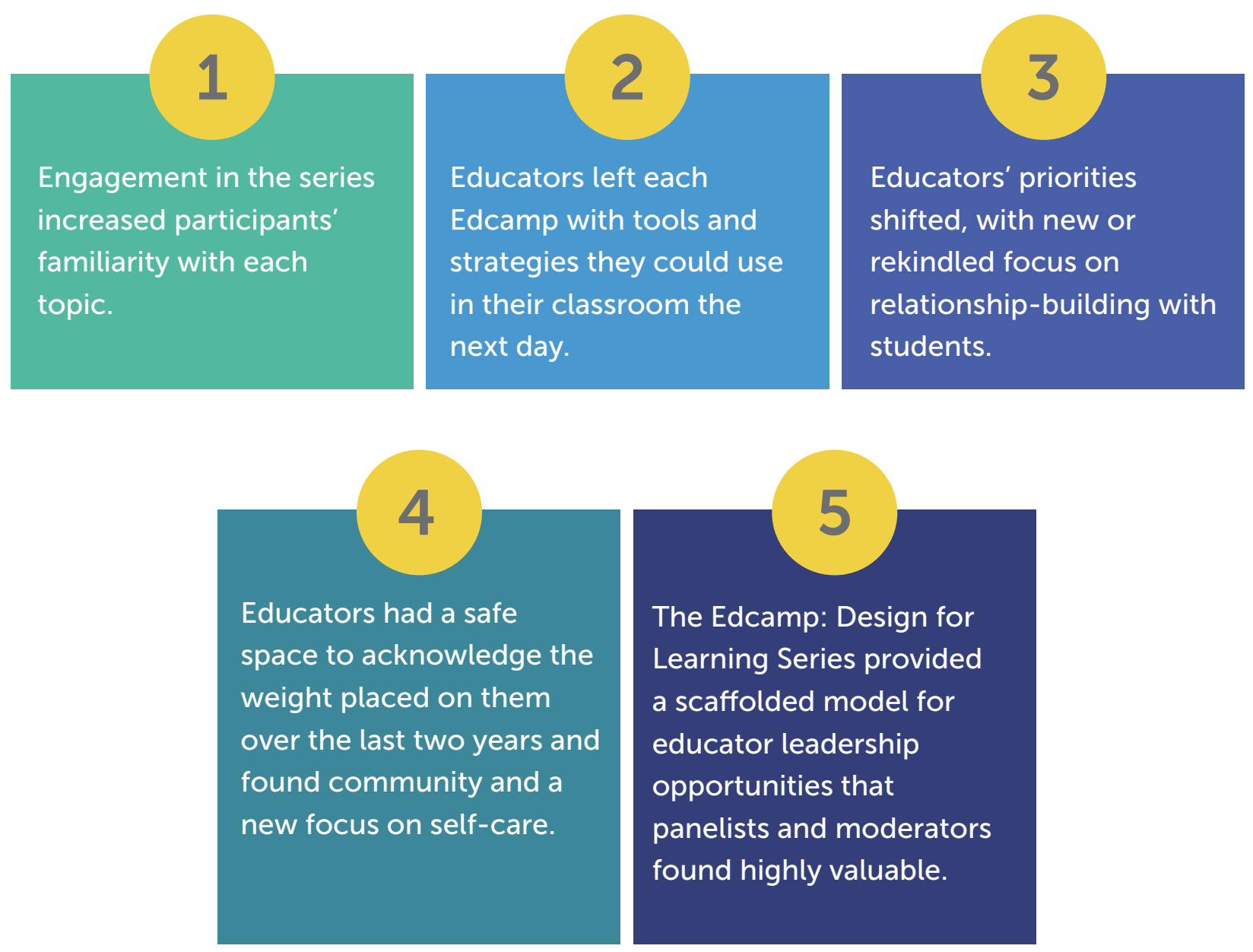

\section{Series Outreach and Study Methodology}

Digital Promise sought to share this opportunity with educators broadly. To accomplish this goal, the Digital Promise team invited educators to join the Edcamp series as participants, panelists, and moderators via Facebook, Eventbrite, and Twitter, as well as through newsletters and email outreach. In total, the series received nearly 1,200 registrations across four Edcamp events. 
With a commitment to learning and iterative improvement, the team invited registrants to complete a pre-survey prior to attending each Edcamp and a post-survey after attending. The surveys included multiple choice and open-ended response questions to better understand the experiences and learnings that came from each event and to compare trends across the series. There was approximately an 80 percent response rate for the pre-survey and a 50 percent response rate for the post-survey. Digital Promise cleaned and coded the quantitative survey questions. In the instances of nominal questions, responses were coded to equal numeric values to enable our team to understand frequency. When questions involved ordinal data, the responses were coded to equate to increasing numeric values (i.e., "strongly disagree" equaled one while "strongly agree" equaled four) to understand frequency and to indicate learning from the pre- to post-survey. Choices that equated to "I don't know" or "neither agree nor disagree" were not included in the analysis. The team also used inductive coding to generate emerging, common themes represented in the open-ended survey questions.

\section{Survey Demographic Data}

The team administered a pre-survey prior to and a post-survey following each Edcamp, amounting to four pre-surveys and four post-surveys. Across eight surveys, we collected more than 500 responses (see Table

1). Approximately 80 percent of survey respondents had previously attended at least one Edcamp (see Table 1). More than 75 percent reported their primary role as in-school educator, including teachers, librarians, and coaches. Five percent reported their primary role as out-of-school educators, such as school or district administrators, school psychologists or counselors, specialists or consultants, parent or community members, tutors, educators in museum settings, and edtech professionals. The majority of respondents work in elementary, middle, or high school settings (see Table 1).

\begin{tabular}{|l|l|l|}
\hline & Pre-Survey & Post-Survey \\
\hline \# Respondents & 327 & 193 \\
\hline Geography & $\begin{array}{l}\text { The series welcomed participants from 22 countries, including Canada and Australia, as well } \\
\text { as countries in South America, the Caribbean, the Middle East, Europe, and South Asia. Among } \\
\text { respondents from the United States, there were } 36 \text { states represented across the mainland. }\end{array}$ \\
\hline $\begin{array}{l}\text { Edcamp } \\
\text { Experience }\end{array}$ & $\begin{array}{l}\text { Over } 80 \text { percent of respondents had } \\
\text { previously attended at least one Edcamp. }\end{array}$ & $\begin{array}{l}\text { Nearly } 80 \text { percent of respondents had previously } \\
\text { attended at least one Edcamp. }\end{array}$ \\
\hline $\begin{array}{l}\text { Learning } \\
\text { Environment }\end{array}$ & $\begin{array}{l}\text { Nearly } 80 \text { percent of respondents work in } \\
\text { elementary, middle, or high schools. About } \\
10 \text { percent work in higher education. }\end{array}$ & $\begin{array}{l}\text { More than 70 percent of respondents work in } \\
\text { elementary, middle, or high schools. 10 percent work } \\
\text { in higher education. }\end{array}$ \\
\hline $\begin{array}{l}\text { Primary } \\
\text { Professional } \\
\text { Role }\end{array}$ & $\begin{array}{l}76 \text { percent of respondents were in-school } \\
\text { educators, including teacher, librarian, } \\
\text { instructional coach. }\end{array}$ & $\begin{array}{l}80 \text { percent of respondents were in-school educators, } \\
\text { including teacher, librarian, instructional coach. }\end{array}$ \\
\hline
\end{tabular}

Table 1. Demographic data across four pre-surveys and four post-surveys administered for the Edcamp Design for Learning series. 


\section{Educators' Years of Experience}

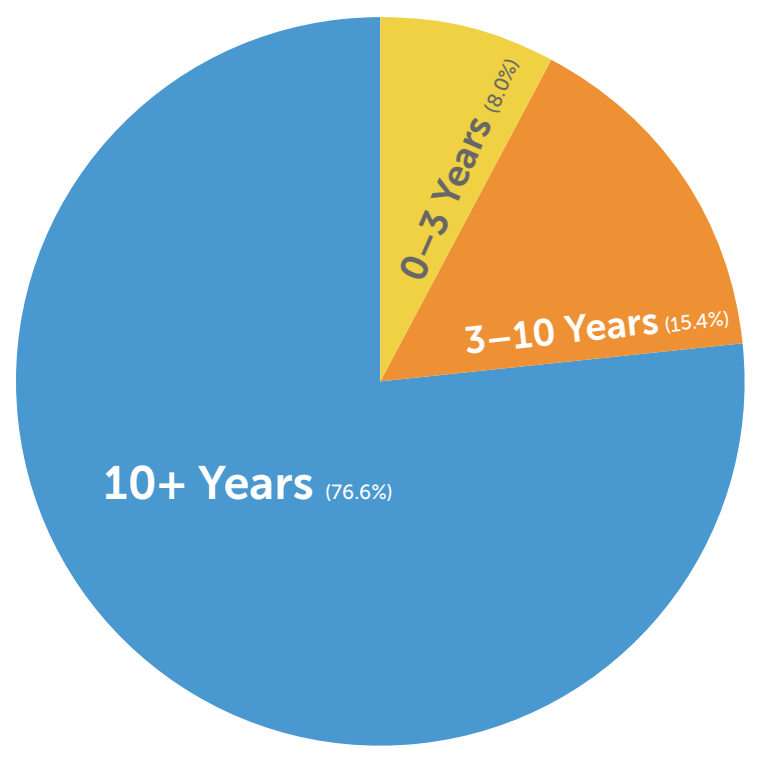

During three of the four events, Digital Promise polled participants to learn more about the professional experience represented in conversations. Poll results found that more than 75 percent of participants have been educators for more than 10 years (see Figure 1).

Figure 1. Edcamp Design for Learning series participants' years of experience as educators.

The following section describes survey analysis across the Edcamp Design for Learning series to identify the impact on teaching and learning.

\section{Series Impact}

The Edcamp Design for Learning series was created to share key insights from Transcend's Science of Learning and Development research with educators by distributing the Designing for Learning Primer and accompanying card deck through the Edcamp Community by Digital Promise. Leaning on the foundational philosophy of Edcamp-participant-driven professional development for teachers by teachers-this series sought to build a bridge between content research and practice. By giving educators autonomy to propose and select educator-led discussion topics, and by creating spaces for foundational learning, collaboration, and connection, the series aimed to establish an empowering approach to professional learning that emphasizes the sharing of research-backed practices.

Prior to and following each session, participants completed a survey to share their goals and learning. Throughout the series, five major themes emerged:

\section{Educators gained increased familiarity with learning science topics.}

The Designing for Learning principle topics discussed in the series are individual variability, identity, motivation, and cognition. Across the four Edcamp events, participants reported an increase in familiarity with each topic (Figure 2). In each post-survey, respondents reported an increase in being very familiar with the topic compared to responses in the pre-surveys; individual variability saw a 17 percent increase, identity saw a 29 percent increase, motivation saw the highest increase of 32 percent, and cognition saw a 21 percent increase (see Figure 2). Survey respondents reported a nearly 20 percent increase in being somewhat familiar with the topic of individual variability. Moreover, after attending the session on motivation, respondents who reported feeling like an expert in the topic doubled. After attending the session on cognition, 
respondents who reported feeling very familiar with the topic doubled to 40 percent and respondents who felt like an expert jumped from one percent in the pre-survey to 11 percent in the post-survey. The entire series resulted in an increase in participants' familiarity with each of the topics.

\section{Change in Familiarity by Session Topic}

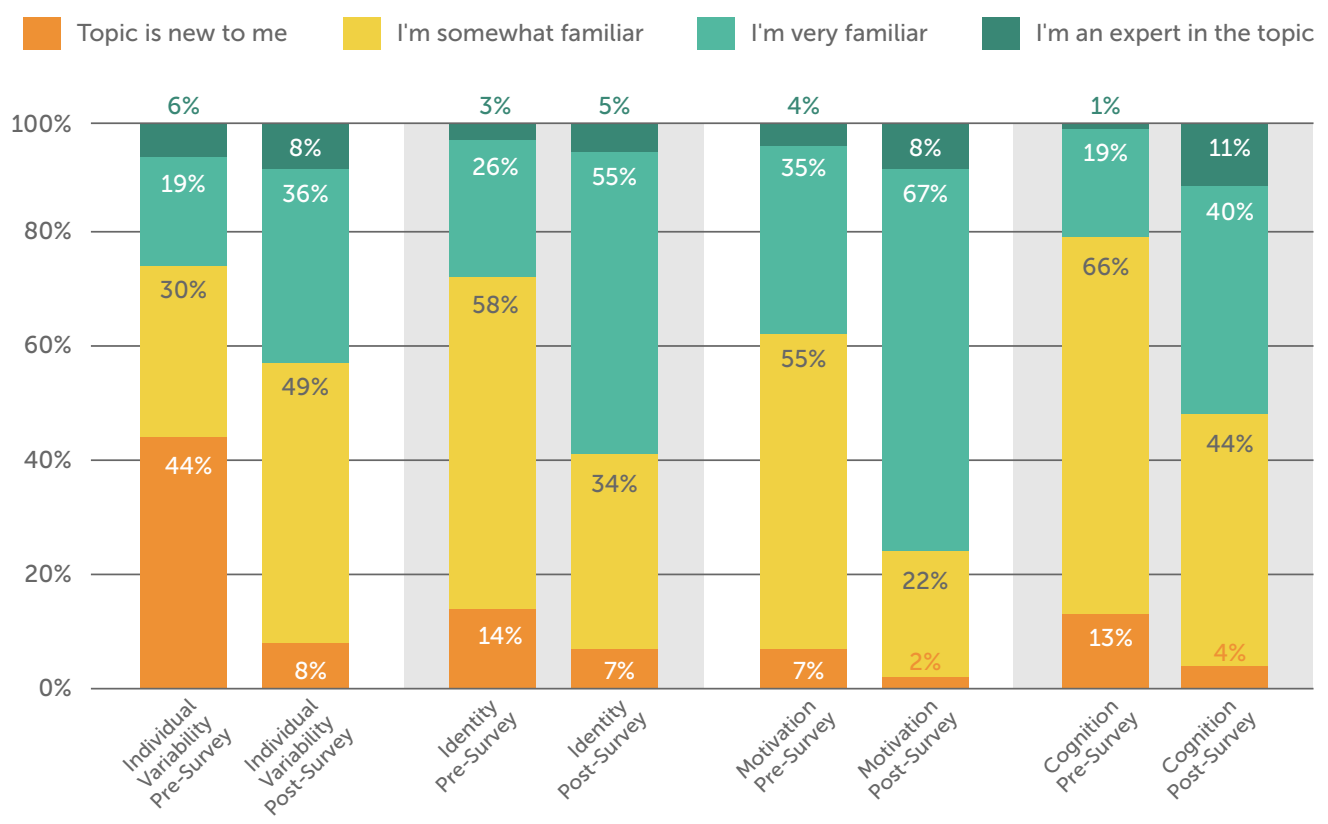

Figure 2. Change in familiarity by session topic from pre-survey to post-survey responses.

In each of the pre-surveys, more than 60 percent of respondents reported that the session topic was either new to them or a topic they are only somewhat familiar with (Figure 3). This finding indicates that while the Edcamp series format provided educators with collaborative, relevant, hands-on professional learning (as Edcamps are known to do), the series also offered participants the chance to explore a topic they may not have had the opportunity to learn about. Data demonstrate that while many participants entered the sessions as novices, they left with a strong sense of familiarity with the topic (see Figure 3). Likely, this substantial shift in familiarity stems from many educators having a deep understanding of the topics in the classroom and using different vocabulary to describe their strategies and questions. This finding suggests that the infusion of learning sciences into the Edcamp model built a bridge between researchers and practitioners. Establishing a shared understanding and language allows educators to dive deeper into the topics and leave the sessions with practical and relevant strategies to support themselves in their professional learning and with their students in classroom settings. 


\section{Comparison of Level of Familiarity in Pre-survey to Post-survey}

Topic is new to me or I'm somewhat familiar

I'm very familiar or an expert in the topic

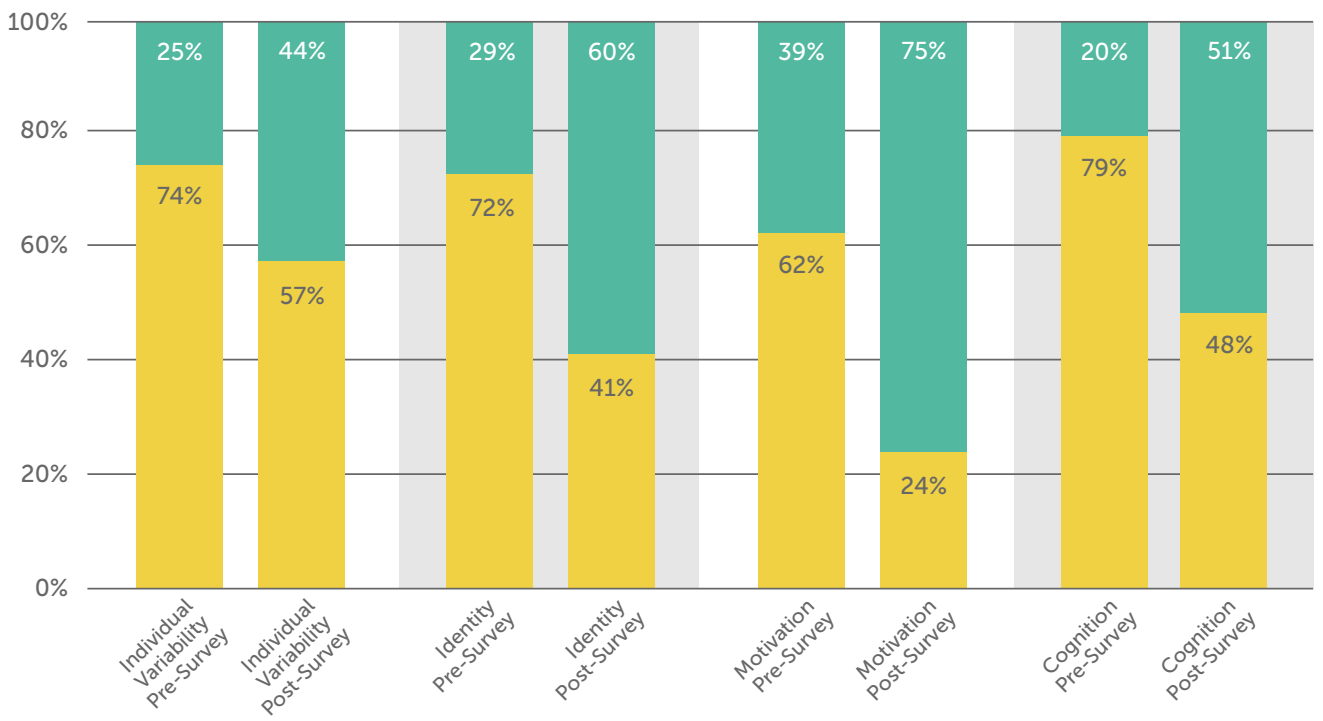

Figure 3. Comparison of pre-survey to post-survey respondents who reported being very familiar with or an expert in the topic compared to respondents who reported that the topic is new to them or they're somewhat familiar with the topic.

Through open-ended survey questions, many participants described the importance of engaging with and learning from peers in this space. This unique approach to centering conversations around learning sciences themes in the Edcamp format preserved educators' autonomy through proposing and creating breakout session topics, while delicately balancing the introduction of new topics that may not have been front of mind for many participants.

\section{Educators learned actionable strategies for the classroom.}

Across nearly every category, survey data suggests that educators left each session with a deeper understanding of the topic and how to leverage their learning to support students. Overall, educators reported the greatest increase in their comfort leveraging their knowledge about the topic to share with peer educators (see Figure 4). For example, 44 percent of respondents reported they agreed or strongly agreed that they were comfortable leveraging their knowledge of individual variability to share with peer educators in the pre-survey, compared to 94 percent in the post-survey. Similarly, in the motivation pre-survey, 57 percent of respondents agreed or strongly agreed with the statement, compared to 96 percent of respondents in the post-survey. 


\section{Change in Level of Agreement From Pre-survey to Post-survey}

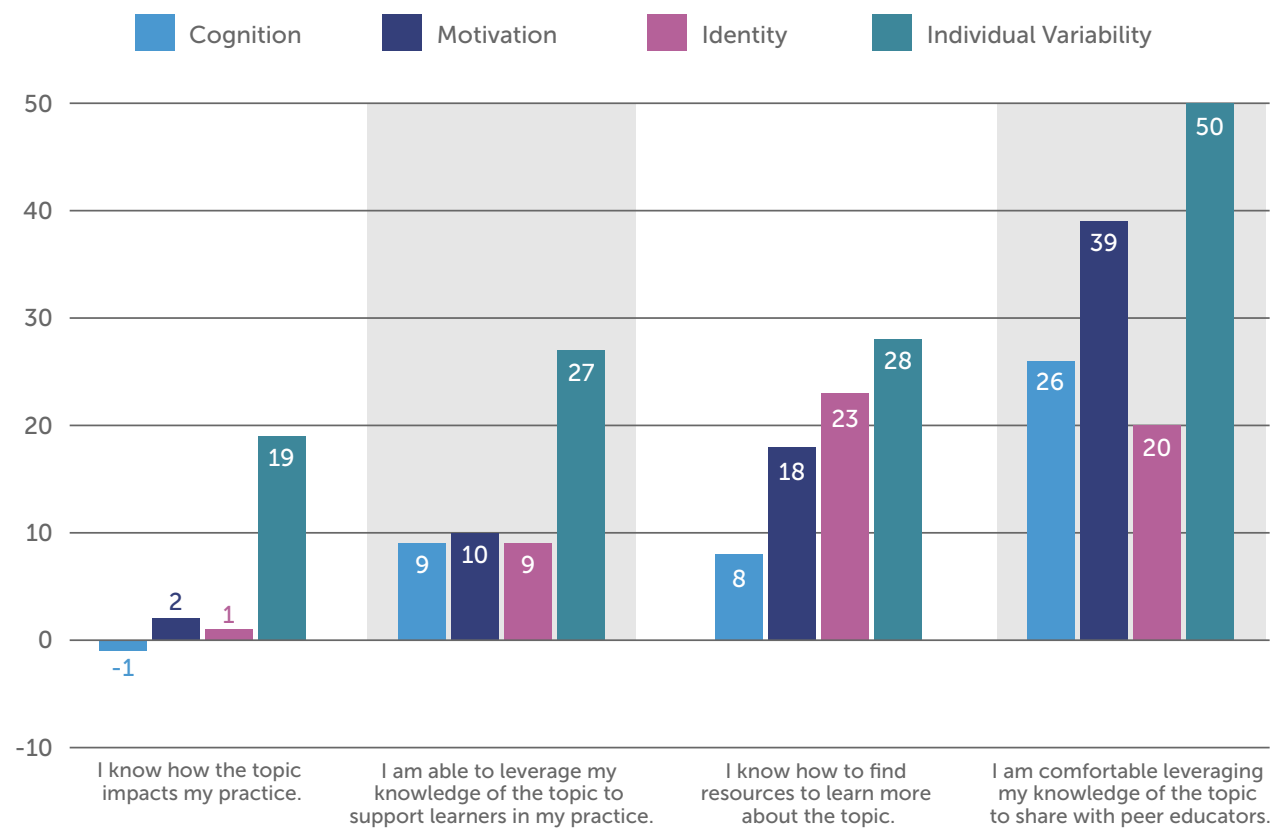

Figure 4. Change in the percentages of participants who agree or strongly agree with the statements in the pre-survey compared to the post-survey.

Educators also reported a substantial increase in their ability to find resources to learn more about the topic (see Figure 3). While 72 percent of respondents agreed or strongly agreed that they knew how to find resources to learn more about the topic of identity in the pre-survey, 95 percent agreed or strongly agreed with the statement in the post-survey. Moreover, only 68 percent of respondents agreed or strongly agreed with the statement in the individual variability pre-sur-

"I will incorporate more voice and choice

in my lessons so that learners can have self-determination."

- Educator Participant vey compared to 96 percent in the post-survey. Data suggest that participants gained a deeper understanding of the topics and were equipped with meaningful resources to continue learning more.

"I plan on using ideas for the beginning of school as well as gaming in the classroom to increase individual variability with my students."

- Educator Participant
Respondents also reported an increase in their ability to leverage their knowledge about the topic to support learners in their practice for each of the four topics. In the individual variability pre-survey, only 69 percent of respondents agreed or strongly agreed with the statement, compared to 96 percent in the post-survey. Motivation also saw a 10 percent increase from pre-survey to post-survey results, jumping from 86 percent of respondents who agreed or strongly agreed in the pre-survey to 96 percent in the post-survey. 
Many educators learned specific strategies, tools, and ideas they planned to incorporate into their practice immediately following participation in an Edcamp. Educators described some of the new tools they planned to bring to the classroom through open-ended survey responses, including student-built rubrics, the Learner Variability Navigator, Universal Design for Learning strategies, NASA STEM resources, visualization strategy, playlists for student choice, leveraging productive struggle, reflection strategy (What? So what? Now what?), and feedback resources.

Aside from specific resources, many discussed new approaches they will incorporate into their practice. In either case, educators reported leaving the Edcamp with relevant and applicable lessons to improve practice.

\section{Educators re-prioritized relationship building with students.}

Educators underscored a core theme of the four Edcamps: a focus on relationship building with learners. While topics varied in content, educators recognized a clear, foundational necessity to understand their learners on an individual level to create safe, respectful, inviting learning

"Focusing on ways for students to anchor their knowledge in new and different ways."

Educator Participant

environments for their students to thrive. Many educators said they intend to prioritize authentic connection with their students. As one educator aptly explained,

\section{Educators found community and support for self-care.}

While the Edcamp model is well-received for offering educators space to drive their own learning in a collaborative, supportive space, the timing of the Edcamp Design for Learning series hit differently.
Kerry Fergason @ifergask

Fabulous conversations this morning at \#EdcampDfL we talked cognition, metacognition, feedback, and reflection strategies. I walked away with some great tools, resources, and idea! Thank you @DigitalPromise

2:12 PM - Oct 23, 2021 - Twitter for Android

\section{A number of educators shared that, from the} experience, they realized they need to lean on community and make time to take care of themselves in order to survive and thrive in their profession. Many shared surprise in realizing that the best way to set their students up for success was coming to the classroom as their best selves. As one educator said,

"My students will benefit from me having renewed impetus to connect with them personally and

to deeply understand their story. This work

is critically important and will take time from

content teaching but will make the content more relevant for the learners."

- Educator Participant
"I recognized that building community amongst students may be the most important thing to do this year, as services have been slashed here."

- Educator Participant "Self-wellness first, then on to meeting the needs of students."

"This session gave me the insight to continue to reflect and learn about what motivates me. Once I know my reason, I can share it with my students."

"Sharing out made me feel better that my challenges are not unique but felt all over education." 
'Getting to hear other educator's 'student first' mentality was refreshing and intriguing. It re-

energized me to go the extra mile to make it

happen for all these kiddos."

- Educator Participant
"It reminded me that there are lots of us out there in this struggle and inspired me to think more positively. (It's been a rough year or two ;)"

\section{Educators gained leadership opportunities and saw their experience as valued.}

Through the Edcamp Design for Learning series, Digital Promise invited educators to join the sessions as panelists, moderators, and/or participants to help co-design topic discussions, share classroom experiences, provide guided conversations in breakout rooms, and engage in the collaborative peer learning

(1) Mrs.N_TeachLovelnspire
@MrsNuble2020
You can not reach the brain, until you reach the heart!
\#EdcampDfl
11:46 AM - Aug 28, 2021 - Twitter for iPhone

environment. While Edcamps typically offer educators the role of organizer or participant, this series aimed to center practitioner voice in sharing learning sciences principles and concepts, and, therefore, created the roles of panelist and moderator to support this goal.

Panelists co-designed the opening educator panel discussion and shared their classroom experiences about the topic and its impact on their teaching practice. Led by partner facilitators, panelists provided real-world examples of how the topic played out in the classroom. Moderators helped keep virtual breakout session conversations focused and productive for everyone, while maintaining brave spaces for all voices. Moderators were asked to participate in a co-design session prior to the Edcamp where they were given resources on the topics, guiding questions, and facilitation tips.

Data suggest that this approach empowered educators who served in the roles of panelists and moderators. In the post-survey, panelists and moderators were asked a few additional questions to help Digital Promise learn more about the experience, and our team was excited to see the results. At least 90 percent of the respondents either agreed or strongly agreed that their experience

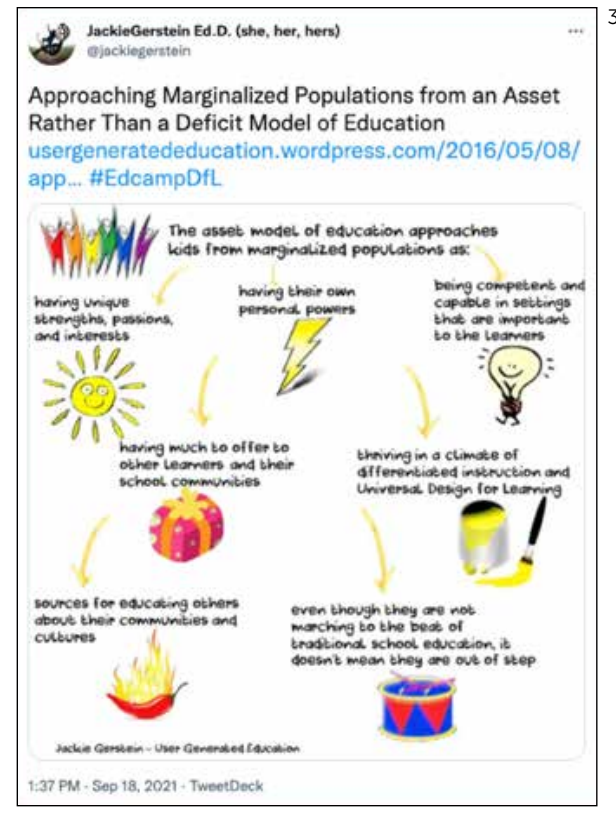
as a panelist or moderator increased their expertise in the topic, increased their confidence to support peers with the topic, and increased their confidence as a leader after serving in their role (see Figure 5). 


\section{Leadership Growth through Edcamp Design for Learning Series}

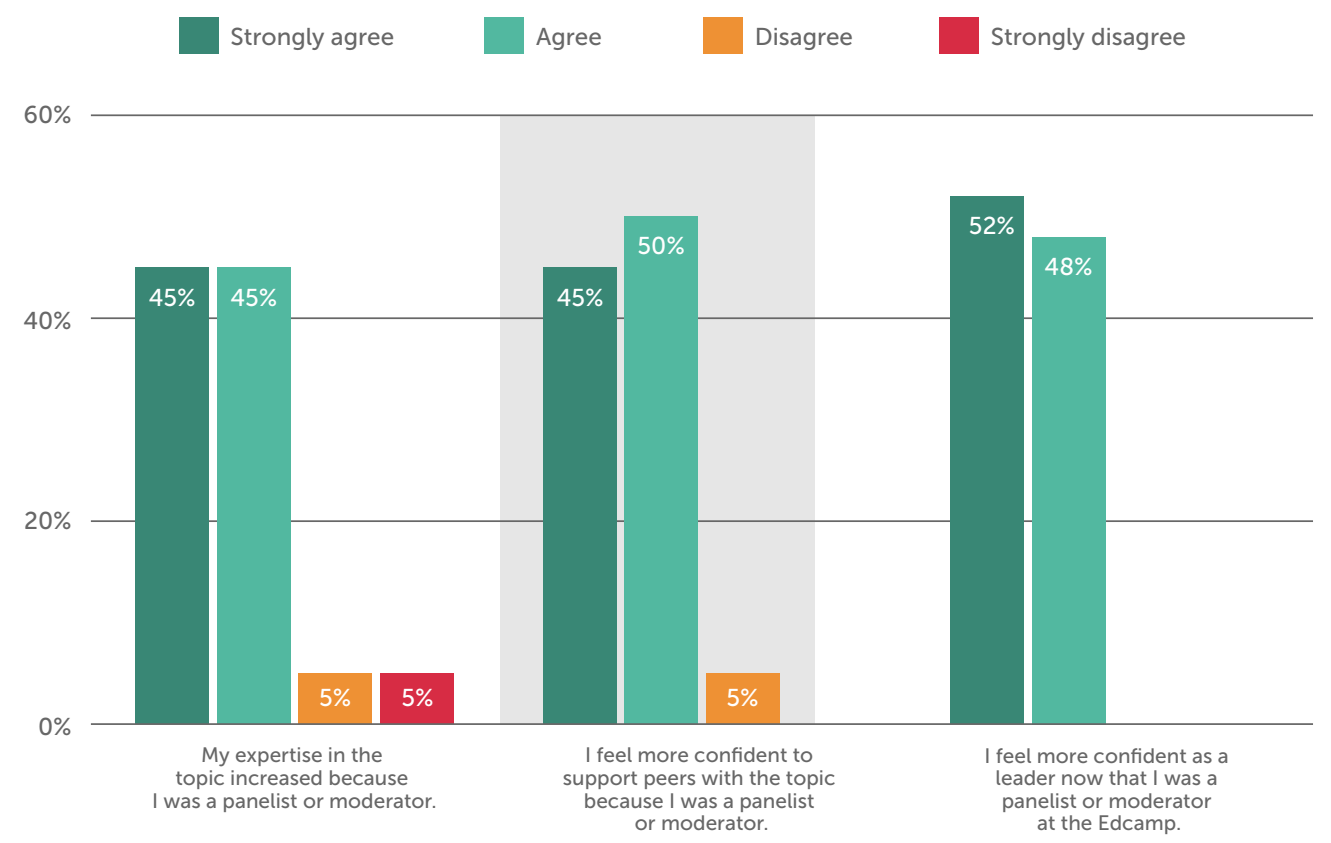

Figure 5. Level of agreement for panel contributors and moderators in the post-survey.

While the Edcamp professional learning model has always been unique in many ways, its focus on empowering educators to be leaders in their profession was well served through this series. By creating scaffolded opportunities to lead through the roles as moderators and panelists, many are well prepared to bring an Edcamp to their own community. In fact, the enthusiasm for leveraging leadership opportunities will continue for many who shared they are interested in learning more about organizing their own Edcamps as a result of participation in this series.

"I understand the concept of cognition, and I also have a plan to organize a kind of Edcamp with the students inspired by the one I have attended."

- Educator Participant 


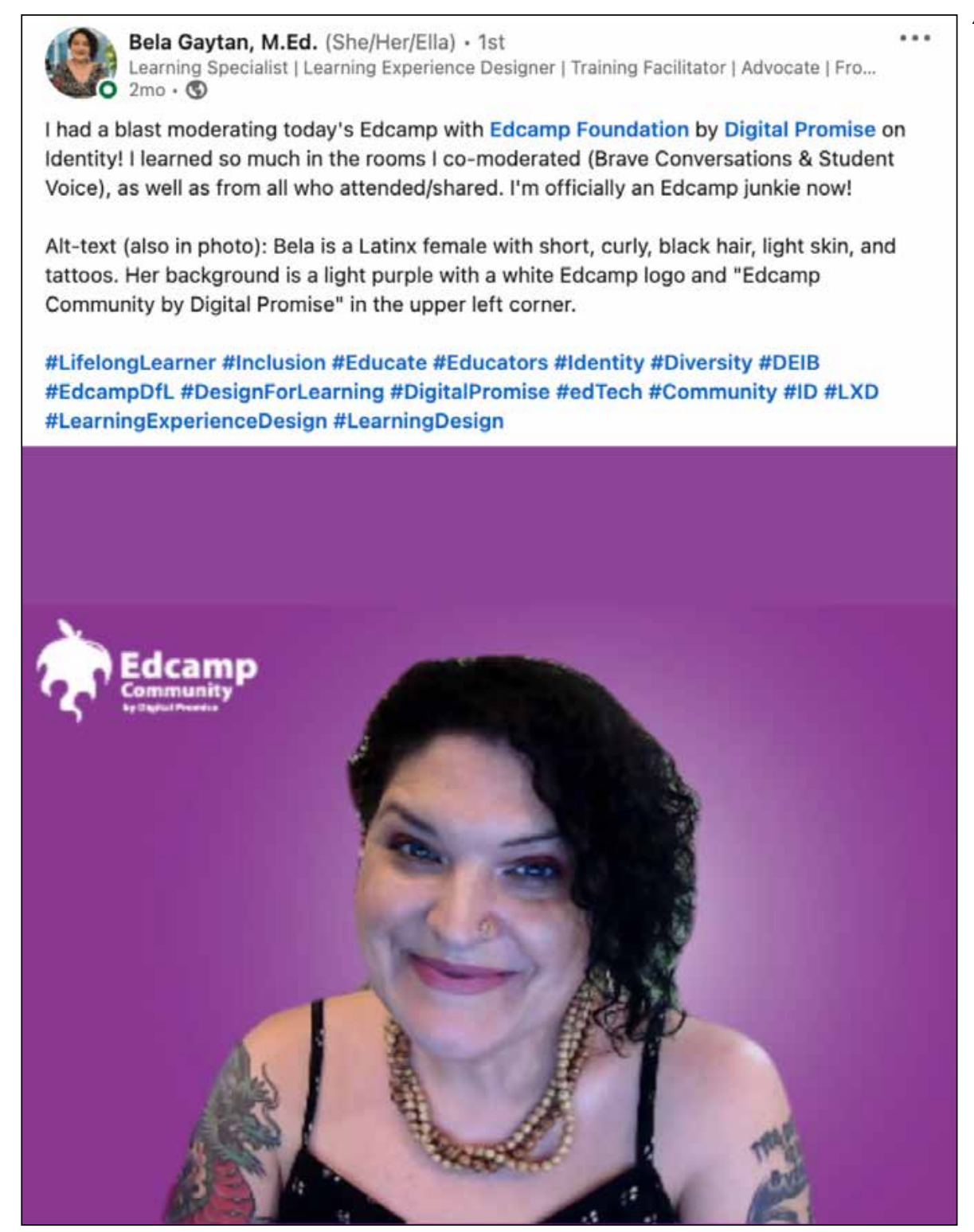

Simply put. I love Edcamp. The discussions that I
participated in warmed my heart and mind.
\#EdcampDfL
1:29 PM - Sep 18, 2021 - Twitter for Android

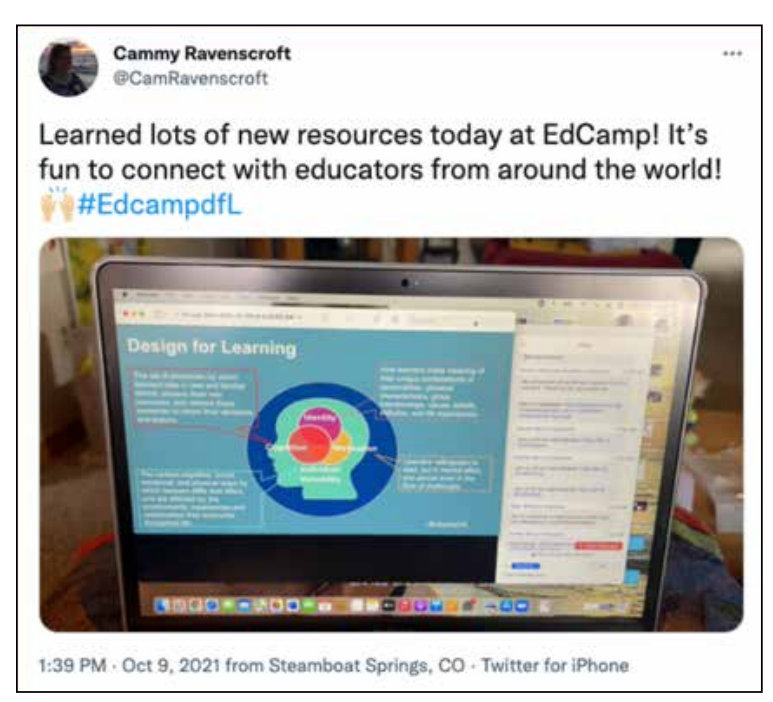

\footnotetext{
${ }^{4}$ https://www.linkedin.com/posts/belagaytan_lifelonglearner-inclusion-educate-activity-6845096467296780288-PaiN

${ }^{5} \mathrm{https} / / /$ twitter.com/mshluvssnoopy/status/1439280515383705602?s $=20$

${ }^{6} \mathrm{https}: / /$ twitter.com/CamRavenscroft/status/1446893120709406721?s=20
} 


\section{Building a Bridge Between Research and Practice That Centers the Learner}

This research-to-practice Edcamp series was an exciting opportunity for the Edcamp Community to center conversations around learning sciences topics. While each session focused on a single topic, educator responses through open-ended survey questions demonstrate that the entire series centered on educators' learning to better support students. Conversations focused on learning science topics and included educator participants in the co-design process where they were offered volunteer opportunities to participate in an educator panel discussion and/or moderate breakout discussions. Selected panelists and moderators were invited to a pre-Edcamp background building session to dive deeper into the topic of discussion, suggest content for Edcamp breakout discussions, and review resources to share with other educators. This iteration of the Edcamp model provided educators with new strategies, a deeper understanding, and, in many cases, a newfound commitment to creating intentionally designed spaces for each learner to thrive and succeed.

The Edcamp Design for Learning series grounded veteran educators' conversations in learning sciences research as more than three-quarters of participants have been in the profession for 10 or more years (see Figure 1). Research suggests that educators are looking for hands-on, relevant, participant-driven learning experiences. And beyond that, we've seen that many experienced educators are also looking for chances to mentor new teachers. The Edcamp model has historically provided that opportunity. With this successful new model, the Edcamp Design for Learning series was able to weave learning sciences research into the professional learning space, while continuing to ensure that educators were driving conversations.

Overall, this series was an experiment to learn whether the concept of merging learning sciences with educator-driven professional development was possible. The Edcamp Design for Learning Series was successful in building engaging opportunities for educators to learn about research-based approaches to thinking and teaching, and for educators to walk away with relevant, practical applications that can be integrated into their practice right away. Educators shared enthusiasm about the experience throughout their surveys and, in some instances, called for more sessions that followed this format. 


\section{Appendix A: Individual Variability}

The first session of the series focused on individual variability. Recognizing that learners differ in varied ways-including their background knowledge, interests, personality, physical abilities, and cultural values - this Edcamp invited educators to share their experiences and expertise as they discussed individual variability in classroom design and instruction. Transcend explains, "A core challenge for our design process is to find creative ways to ensure that learners' individual profiles are deeply understood and responded to by the surrounding learning environment." While focusing on life experiences, developmental state, and learning differences, we held space for discussions, sharing, and networking to build a community among educators interested in designing learning experiences with individual variability in mind. Through the pre-survey, many educators shared that they were attending to learn more about current best practices for teaching, particularly in the COVID era. Others expressed interest in better understanding the topic and how individual variability can be leveraged to support learners. Finally, some shared their enthusiasm for the space to engage in thought partnership with peers and learning new ways to leverage edtech:

- "Gaining more on how to help students gain more confidence in themselves and want to succeed."

- "I would like ideas for how to allow students to demonstrate mastery in different and authentic ways."

- "To better understand how to assess individual variability and how to address it."

- "I honestly enjoy talking with other colleagues around the country and continuing to grow as an educator and as an individual."

By comparing responses from the pre-survey to those in the post-survey, we saw that educators gained familiarity with the topic. While nearly 44 percent of respondents said that individual variability was new to them in the pre-survey, almost 50 percent of respondents reported being somewhat familiar with the topic in the post-survey (see Figure 6). In fact, there was nearly a 20 percent increase in respondents who reported being very familiar with the topic from the pre- to post-survey (see Figure 6).

\section{Participants' Level of Familiarity Related to Individual Variability}

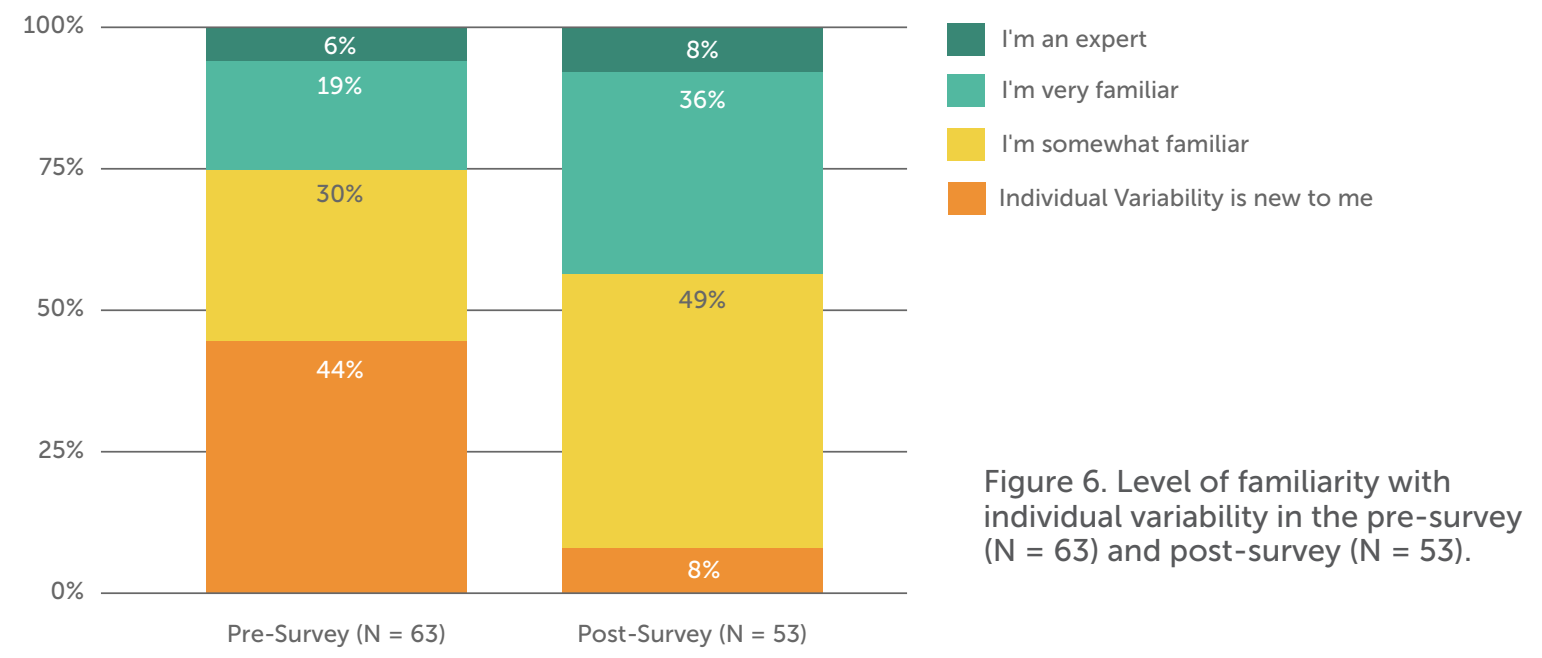


Comparing responses from the pre- to post-surveys provided evidence that not only were educators introduced to new language to describe the concept of individual variability, but also that the Edcamp session supported them in learning how individual variability impacts their practice, how to leverage their knowledge to support learners, and how to find resources to learn more (see Figure 7). While only 44 percent of respondents reported they agreed or strongly agreed that they felt comfortable leveraging their knowledge about individual variability to share with peer educators, we saw a 50 percent increase in the post-survey. Meaning, 94 percent of respondents reported they agreed or strongly agreed that they felt comfortable leveraging their knowledge of individual variability to share with peer educators (see Figure 7).

\section{Pre-to Post-survey Comparison of Respondents Who Agree or Strongly Agree}

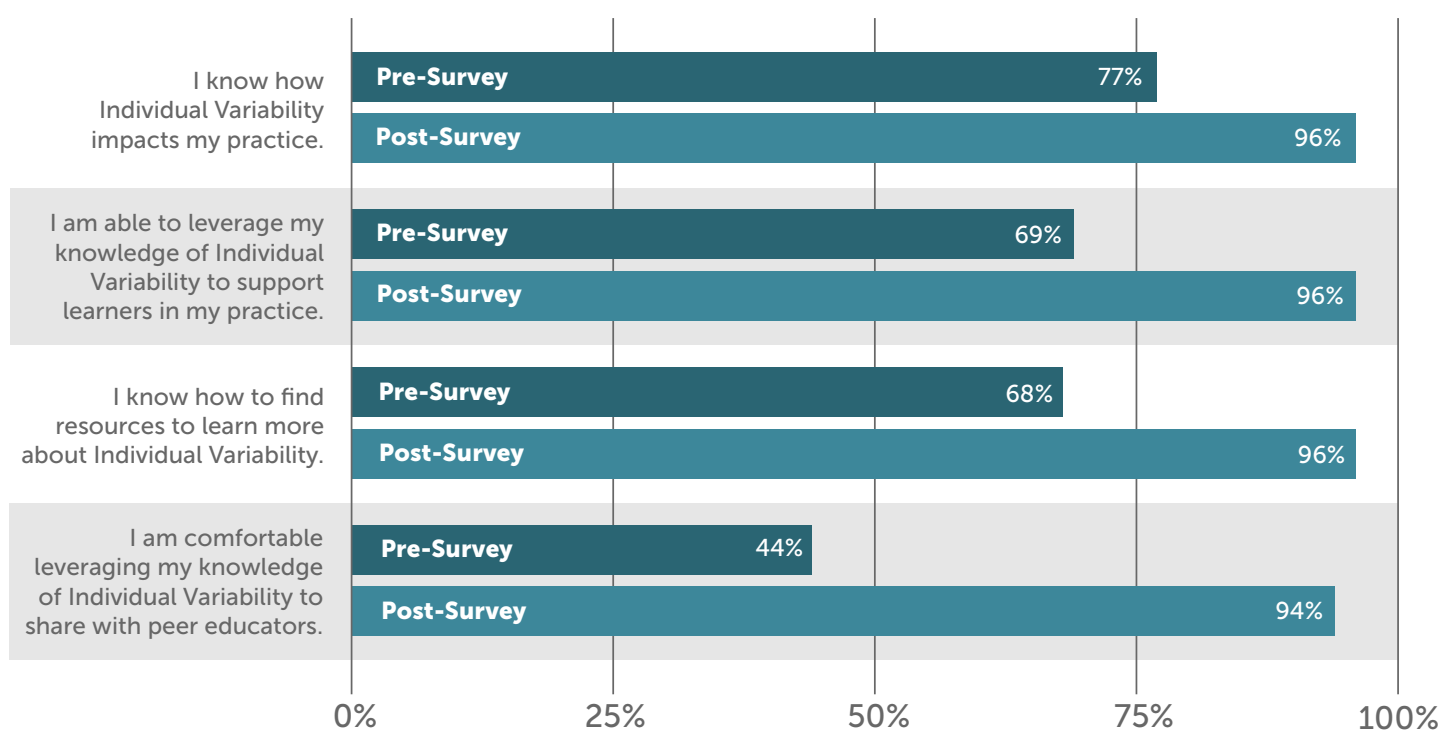

Figure 7. Percentage of respondents who reported they agree or strongly agree with the statement, comparing responses from the pre-survey to the post-survey.

Through the post-survey, educators shared more about how their learning will impact their practice and their learners. Many shared that the experience will impact their learners by helping educators better understand how to meet each learner where they are, establishing a "student first" mentality, and focusing on differentiation and engagement. Moreover, many expressed that, from the Edcamp experience, they've learned to focus on community and relationship building, identify strategies to better establish learner supports, understand teaching strategies to address learner variability, and see students as whole learners. Some shared that they felt supported connecting with other educators who have survived the last two school years. Many also appreciated the resources and ideas they gained from the experience:

- "Taking time to get to know my students individually."

- "One thing I will incorporate is choice boards and more differentiation."

- "Designing learning experiences to educate the whole student." 


\section{Appendix B: Identity}

The second session of the series focused on identity. For learners to maximize their learning, we believe they must have a secure sense of identity that includes self-understanding, a sense of belonging, and an ability to navigate identity threats. Transcend explains, "As designers, it's our role to create environments where learners are able to explore questions of identity, express who they are, feel affirmed, and reconceive themselves as individuals capable of learning and success." Through this Edcamp, we invited educators to share their experiences and expertise about identity in classroom design and practice while emphasizing that learning environments must be built to account for learners' various simultaneous identities.

In the pre-survey, educators shared that they hoped to: learn more about the topic; improve their practice through self-reflection and collaboration; better support learners by increasing student engagement, motivation, and confidence; empower student voice; create a welcoming environment to provide space for learners to explore their own identities; and access new resources, tools, and ideas. Many elaborated on their hopes for the session:

- "Identifying aspects of my own identity that create bias within my teaching and obstacles for my students."

- "I would like to expand my understanding of how identities play out in classrooms among educators and students, and the barriers we face, as educators, to creating authenticity."

- "Co-develop actionable techniques for connecting with students and creating a safe classroom space for them to explore and express their identity."

Respondents reported nearly a 30 percent increase in feeling very familiar with the topic of identity between the pre- and post-surveys (see Figure 8). While pre-survey responses made it evident that the concept of identity was something many educators (58 percent) were somewhat familiar with, post-survey data demonstrate that participating in the session increased the depth of educators' understanding around the ways identity impacts students (see Figure 8).

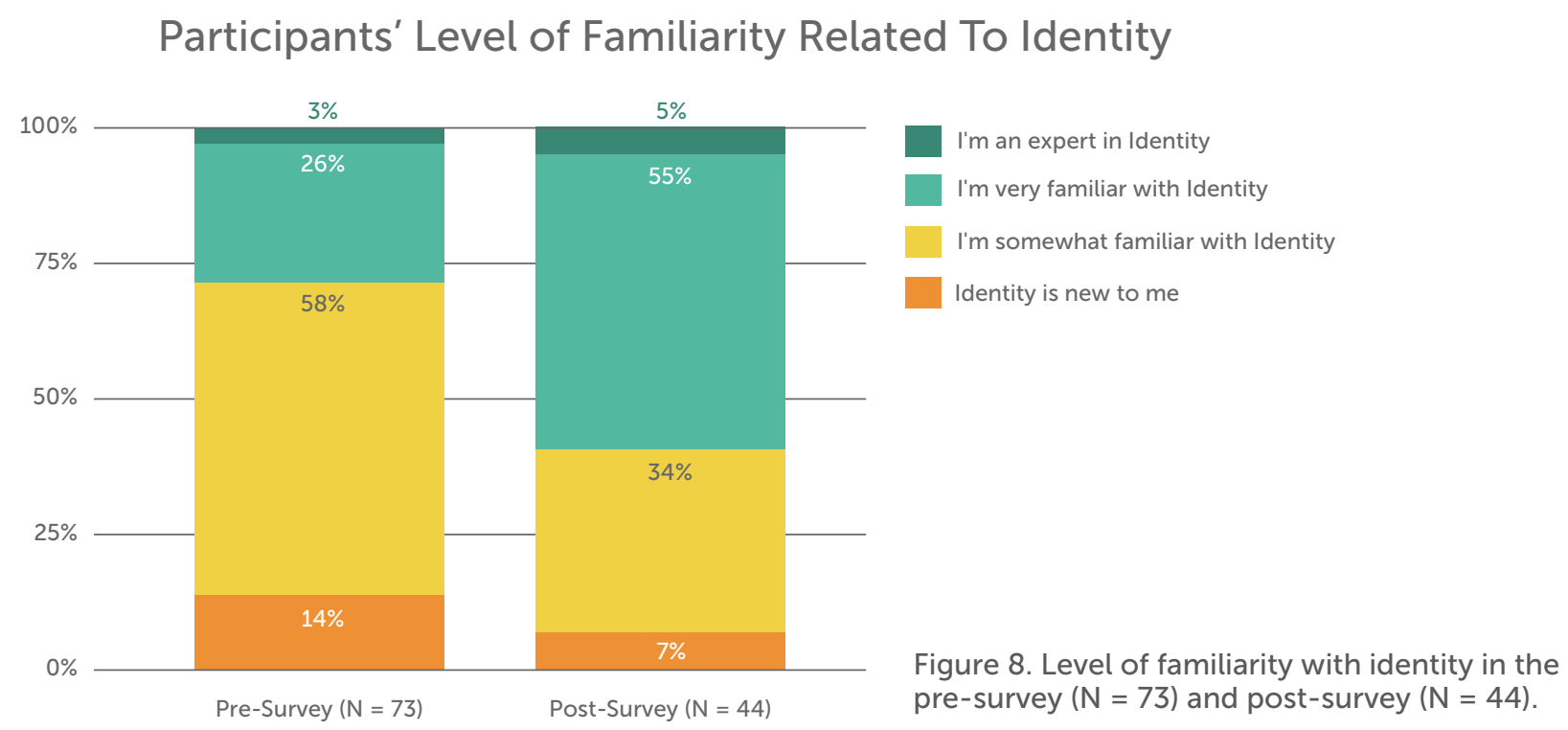


Between the pre- and post- surveys, there was nearly a 10 percent increase in respondents who reported they agreed or strongly agreed that they had ability to leverage their knowledge of identity to support learners in their practice (see Figure 9). Moreover, 20 percent more respondents in the post-survey agreed or strongly agreed that they could find resources to learn more about identity and that they felt comfortable leveraging their knowledge about identity to share with peer educators compared to the pre-survey (see Figure 9).

\section{Pre- to Post-survey Comparison of Respondents Who Agree or Strongly Agree}

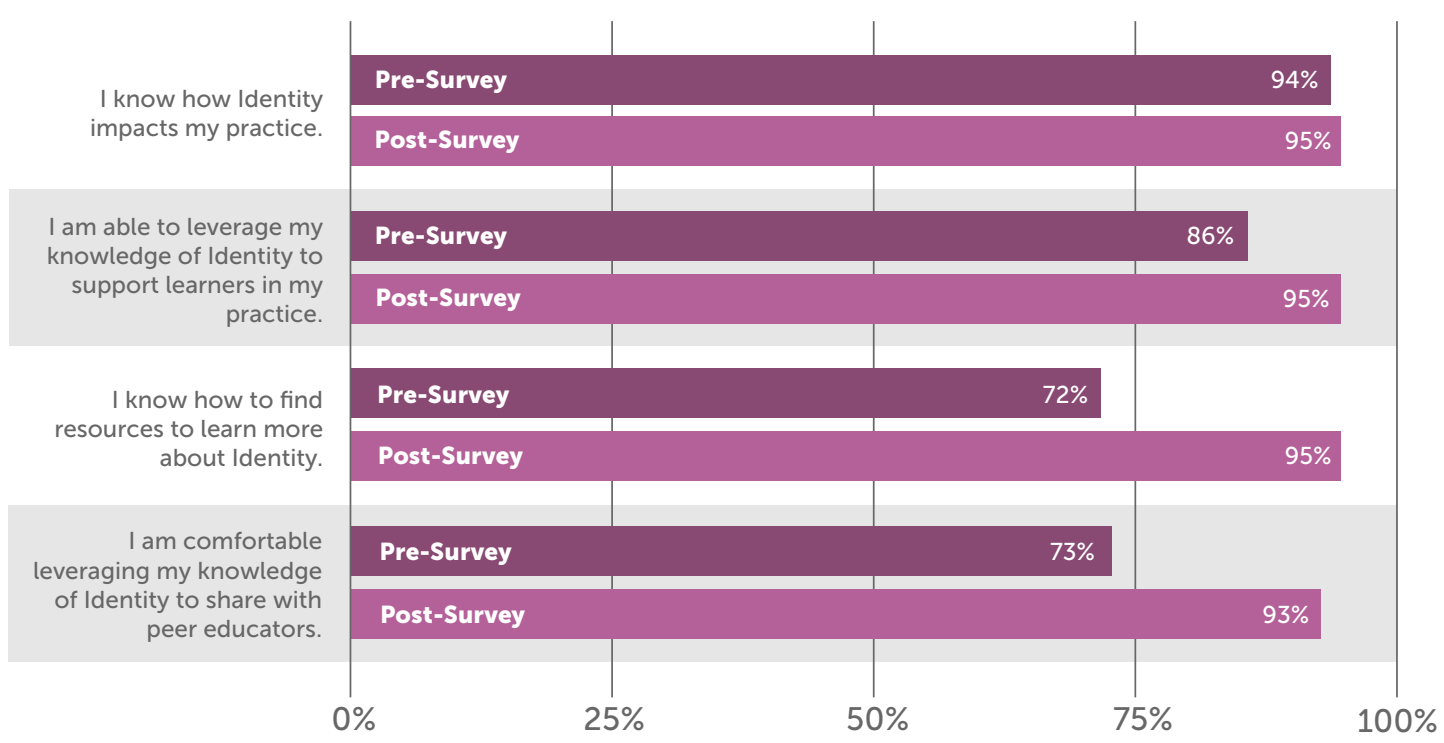

Figure 9. Percentage of respondents who reported they agree or strongly agree with the statement, comparing responses from the pre-survey to the post-survey.

Through the post-survey, educators were invited to share more about the ways they will use their learning to support learners and impact their practice. Many educators walked away from the session with strategies to create a safe environment for learners to explore and express their identities and to create more culturally responsive lessons, while others learned to prioritize empathy and focus on building stronger connections with their learners. For some, the experience helped them see how identity is always present in the classroom and should be thoughtfully considered. Many also shared that they walked away with strategies and tools to support students, such as zen countdowns and social-emotional learning activities:

- "I believe my advisory and students will have many opportunities to openly discuss topics without judgment, listening to one another to create a loving, compassionate environment."

- "I will be more intentional about questions of access and implicit functions of culture that may impact identity and comfort sharing identity."

- "After this session, no one should own a pair of rose-tinted glasses. The conversations that I was privy to allowed my mind and heart to open."

- "I have more resources to continue building my personal resilience, check my biases, and build a stronger community in my classroom." 


\section{Appendix C: Motivation}

The third session of the series focused on motivation. Without motivation, the hard work of learning is not sustainable. While personal for each learner, motivation is essential to getting started and persisting until the end, despite challenges. Transcend explains, "Since nothing happens without motivation, one of our central goals as designers should be to support motivation with each learner, whether this means sustaining learners' natural curiosity and motivation, helping to expand on it, or removing barriers to it." At this Edcamp, we invited educators to share their experiences and expertise as they discussed motivation in classroom design and practice, considering the main factors that can drive or block motivation: value, self-efficacy, sense of control, and constructive emotions.

In the pre-survey, educators shared their drive to join the session, including learning new strategies to motivate and connect, collaborate with peers, and access new tools, resources, and strategies:

- "To learn more about motivating learners in order to create more inclusive and varied learning content".

- "I want to find ways to motivate my students and myself, intrinsically and extrinsically."

- "I'm interested in seeing how other teachers are mentally getting through this difficult school year. I am also interested in seeing how teachers are actively keeping students engaged both on e-learning and in person."

- "Add some new strategies and tools to my professional understanding of motivation in this context."

By comparing responses from the pre-survey to those in the post-survey, we saw that educators gained familiarity with the topic. While 55 percent of respondents said that they were somewhat familiar with the topic of motivation in the pre-survey, almost 70 percent of respondents reported being very familiar with the topic in the post-survey (see Figure 10). In fact, respondents who reported being experts in the topic doubled from the pre- to post-survey (see Figure 10).

\section{Participants' Level of Familiarity Related To Motivation}

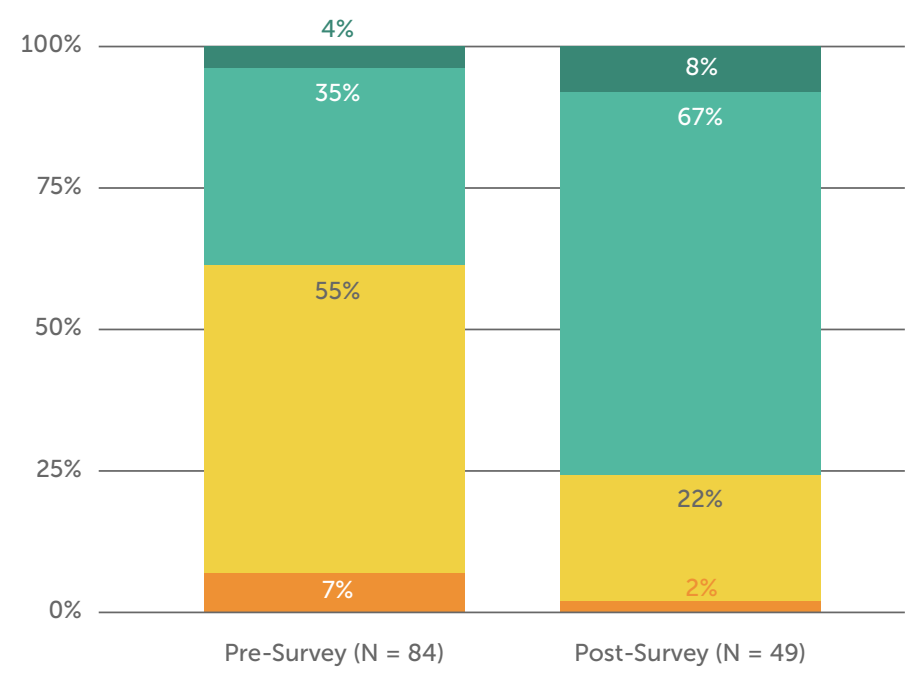

Figure 10. Level of familiarity with motivation in the pre-survey $(\mathrm{N}=84)$ and post-survey $(\mathrm{N}=49)$. 
Between the pre- and post-surveys, nearly 20 percent more respondents reported they strongly agree that they know how motivation impacts their practice and are able to leverage their knowledge about motivation to support learners in their practice (see Figure 11). Moreover, nearly 20 percent more respondents reported they agree or strongly agree that they know how to find resources to learn more about motivation in the post-survey compared to the pre-survey (see Figure 12). Excitingly, we saw a nearly 40 percent increase in the percentage of respondents who agree or strongly agree that after attending the Edcamp, they are comfortable leveraging their knowledge of motivation to share with peer educators (see Figure 12).

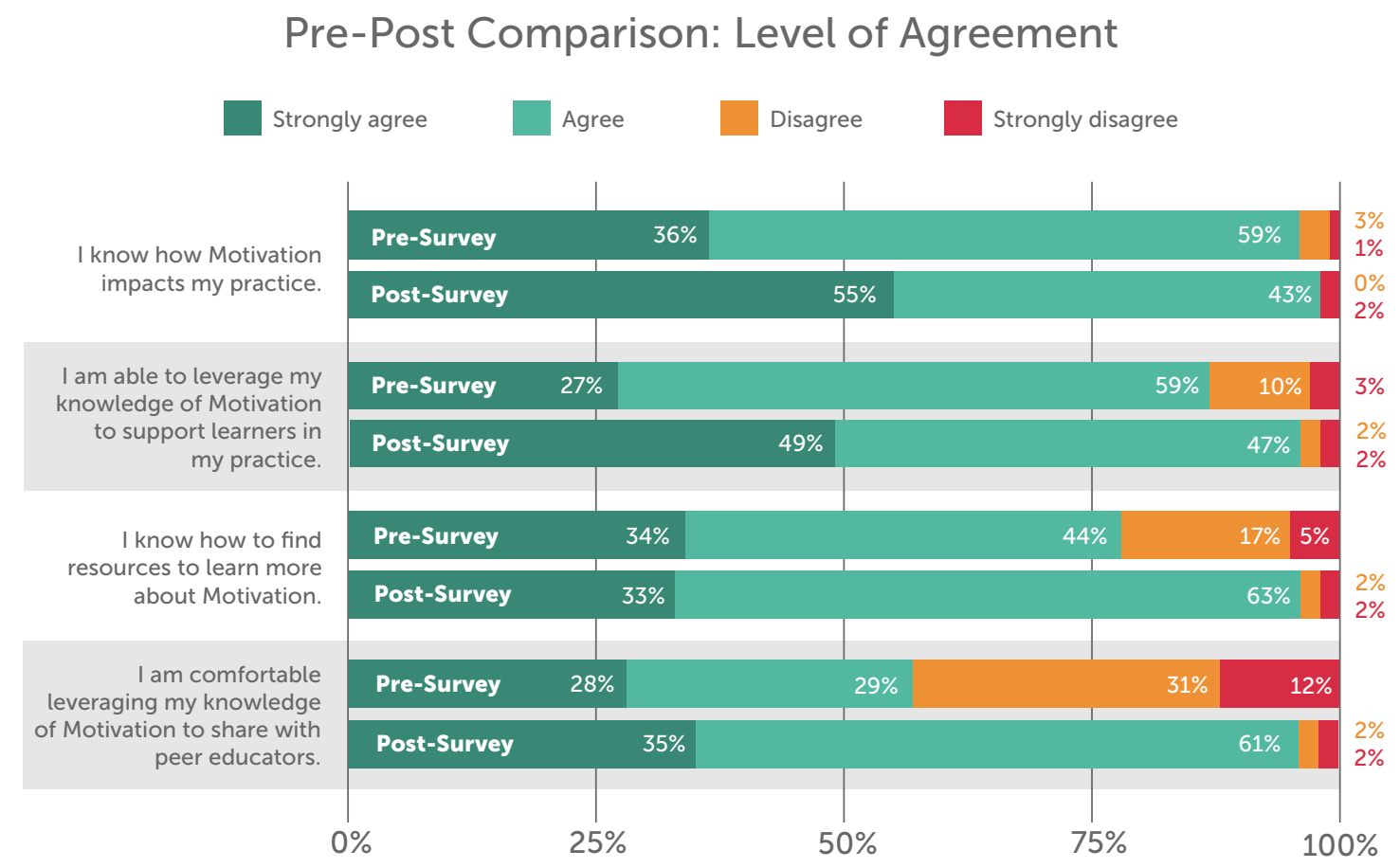

Figure 11. Comparison of the level of agreement for statements from the pre-survey to the post-survey.

\section{Pre- to Post-survey Comparison of Respondents Who Agree or Strongly Agree}

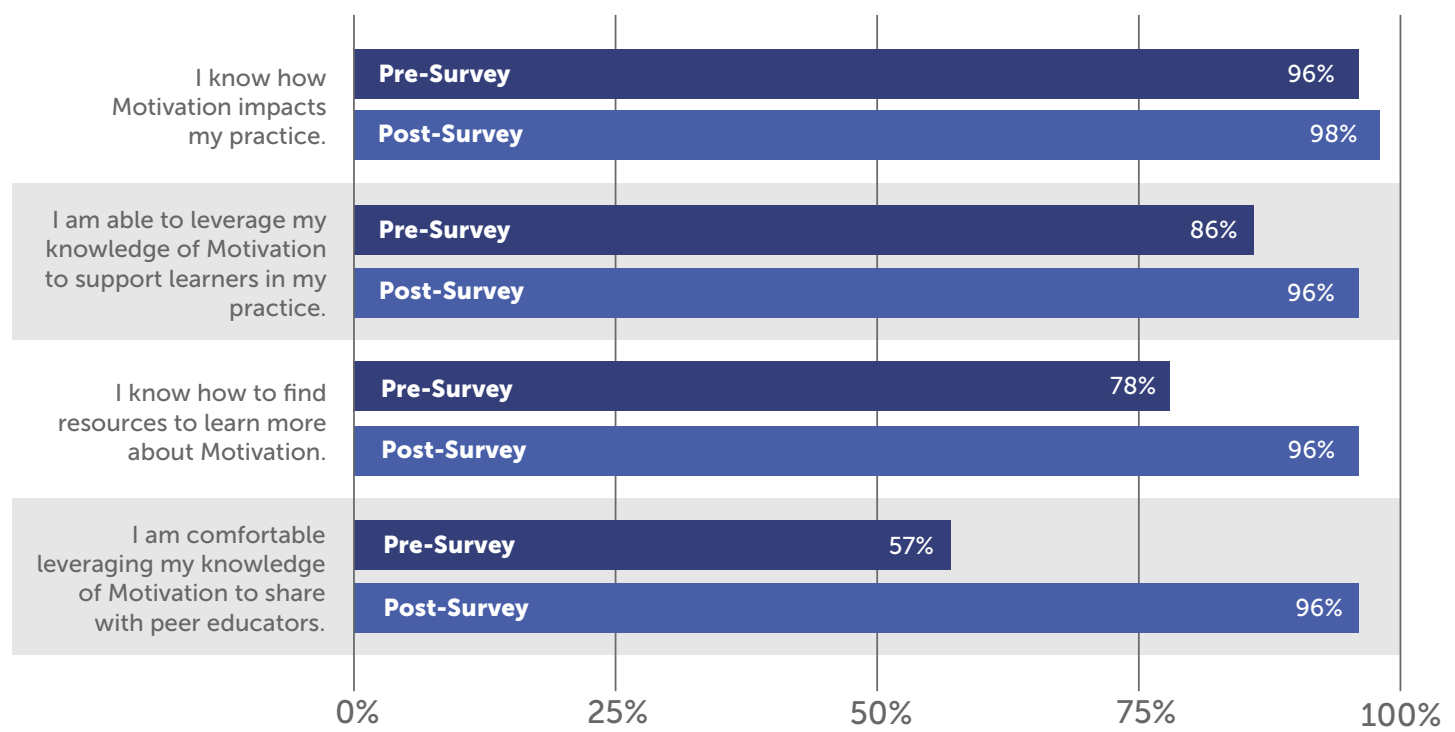

Figure 12. Percentage of respondents who reported they agree or strongly agree with the statement, comparing responses from the pre-survey to the post-survey. 
Through the post-survey, educators shared more about how their learning will impact their practice and their learners. Educators shared that the experience will impact students through their newly learned ability to better motivate, to establish, foster, and prioritize meaningful connections with learners, and to create more learner choice. Further, educators shared that, through the session, they learned the importance of prioritizing their own self-wellness to ultimately show up for and support their students. Educators also shared that through the experience they gained access to valuable tools and resources, strategies, and a deeper understanding of the topic of motivation:

- "It will give them a better chance of being motivated in the classroom because I am more aware of how to motivate them."

- "I feel more confident in the areas where I'm putting my effort most to reach my students. I also think I have new resources and activities to use in my classroom that are motivating."

- "Unique ways to foster connections with each learner, specific to their backgrounds and what motivates them." 


\section{Appendix D: Cognition}

The final session of the series focused on cognition. This Edcamp invited educators to share their experiences and expertise as they discussed the importance of cognition in classroom design and practice specific to the following principles: focused attention, manageable cognitive load, meaningful encoding, effective practice, high-quality feedback, and metacognitive thinking. Transcend explains, "Learning is hard work. It requires that individuals actively notice, grapple with, remember, apply, and expand on new content and experiences. This involves complex cognitive processes like attention, encoding, and retrieval that occur through a relationship between working memory and long-term memory." Together, we co-designed space for discussions, sharing, and networking while building a community among educators interested in designing learning experiences with cognition in mind.

In the pre-survey, educators shared their drive to join the session, including gaining a better understanding of cognition to support learners, accessing new resources, strategies, and ideas, and collaborating with peers:

- "I want to learn how to enable my students to be better self-learners using some of the practices presented in this Edcamp."

- "Learning how to engage students in metacognition and building lessons with multiple response options."

- "Learn how to better address the current trauma the COVID-19 pandemic has had on managing cognitive load."

There was an increase in respondents' familiarity with cognition between the pre- and post-surveys. Respondents who reported feeling very familiar with cognition doubled after engaging in the Edcamp session (see Figure 13). Further, respondents who reported feeling like an expert in cognition jumped from one to 11 percent after attending the session, and respondents who reported that cognition was new to them dropped from 13 to four percent following the session (see Figure 13).

\section{Participants' Level of Familiarity Related to Cognition}

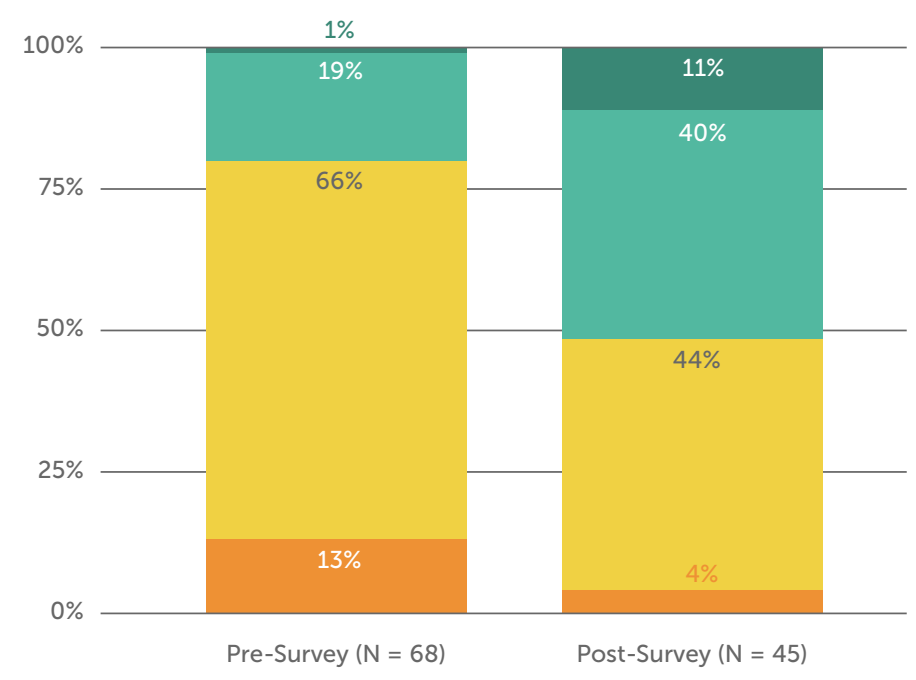

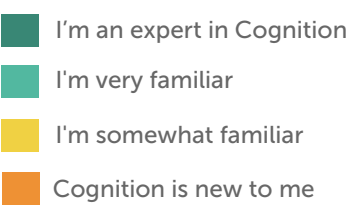

Figure 13. Level of familiarity with cognition in the pre-survey $(\mathrm{N}=68)$ and post-survey $(\mathrm{N}=45)$. 
Beyond familiarity with the concept of cognition, the data demonstrate that participation in this Edcamp session supported educators in learning how to leverage their knowledge about cognition to support learners and how to find resources to learn more (see Figure 14). Additionally, there was a reported increase in educators' comfort leveraging their knowledge about cognition to share with peer educators (see Figure 14).

\section{Pre to Post-survey Comparison of Respondents Who Agree or Strongly Agree}

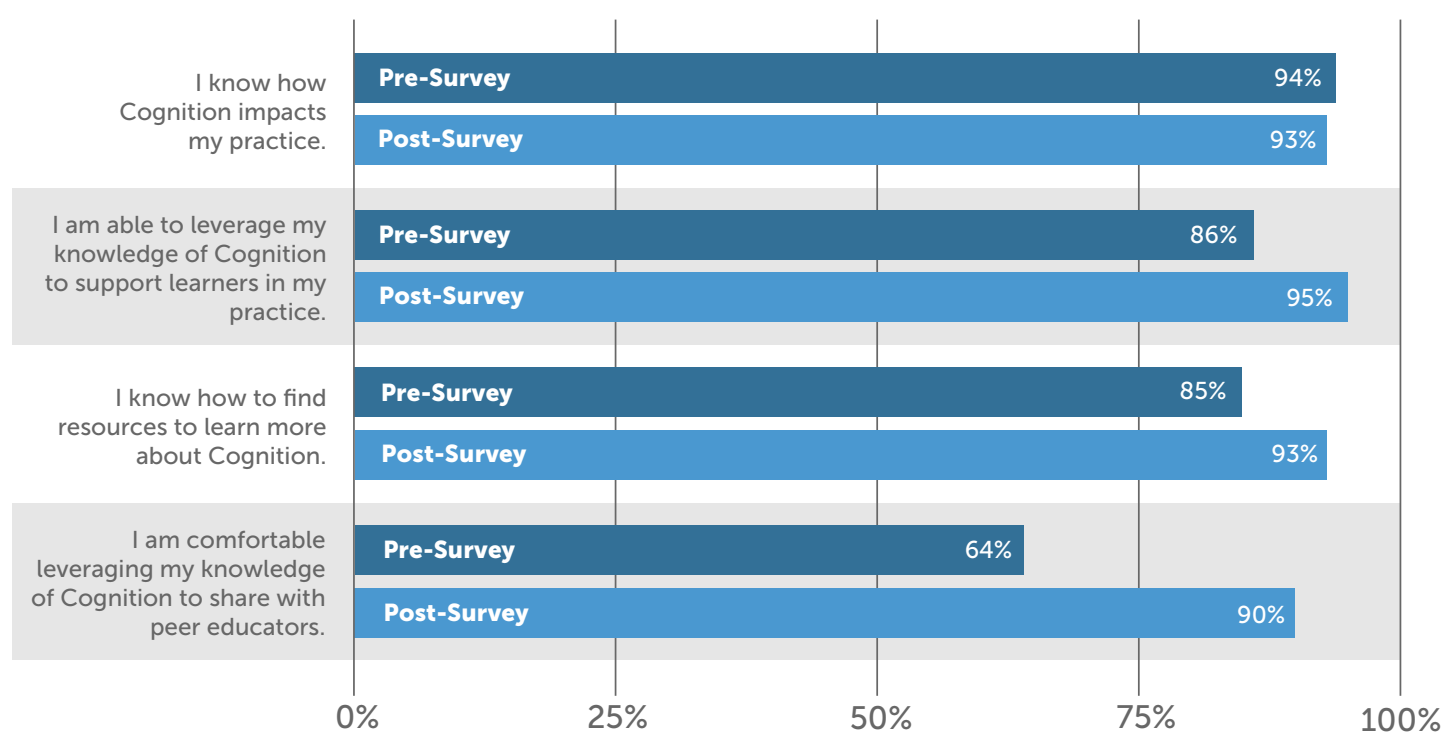

Figure 14. Percentage of respondents who reported they agree or strongly agree with the statement, comparing responses from the pre-survey to the post-survey.

Through open-ended questions in the post-survey, educators provided greater detail around the ways their learning from the session will impact their learners and their practice. Many shared a newfound ability to leverage knowledge of cognition for learners along with a deeper understanding of cognition. Many also reflected on their better understanding of how to connect with and support learners through prioritizing relationship building and new strategies and resources to better support learners, such as student-built rubrics, feedback, visualization strategy, and reflection strategies (like What? So what? Now what?). Finally, some educators reported that the space to collaborate was valuable to learn from others who have experienced similar challenges over the last two years:

- "I will offer them more voice and choice and that will give them a better opportunity to cement their learning and value what they know and can learn."

- "Really encouraged me to look into metacognition more, and gave me techniques as a starting point both for classroom practice and research."

- "I will provide them with more group work to build community and create games for the whole school to use."

- "Building relationships and discovering students' interests is a great way to foster learning and provide clarification when needed. I can refer back to what students are familiar with to provide an understanding."

- "I learned that hands-on experiences in learning helps them to focus and lead their own learning. It is important how students absorb learning. Getting to know students and their interests is important when building relationships with them." 


\section{Dedication Page}

The Edcamp Community team would like to thank educators for their continued dedication to their learners during these unprecedented times. Through this case study, we witnessed hundreds of educators coming together virtually on Saturdays to learn from one another, share resources and ideas, and build powerful relationships with other educators across the globe. We thank them for their participation! More importantly, we want to thank and acknowledge the educators who volunteered to participate in the educator panel discussions and to serve as breakout session moderators during the Edcamp: Design for Learning Series. We couldn't have done it without you.

\section{Educator Panel Contributors:}

Jaida Campbell
Candace Cox-Wimberley
Dr. Angela Elkordy
Elizabeth Gates
Erin Haywood

Moderators:

Dr. Mamzelle Adolphine

Theresa Agostinelli

Nurun Begum

Tara Bova

Stacia Burrowes

Mar Cano

Anna Curtis

Brenda Dunn

Shernette Dunn

Nanette Fandino-Diaz

Kerry Fergason

Ruth Flores

Vidhya Ganesaneee
Anni Kumar

Alexis Lewis

Godwyn Morris

Michellea Millis Rucker

Aggie Salter

Bela Gaytan
Jackie Gerstein
Jen Gripman
Sue Hellman
Sabina Ibraheem
Susan Jones
Haeun Kim
Melissa Krenzer
Johari Mitchell
Paul O'Neill
Uy Phi
Kate Robinson
Michellea Millis Rucker

Dr. Nicole

Stephens

Rachael Wilcox

Michelle Wooten

Elvira Salazar

Abigail Schifer

Naiobe Sharrock

Cynthia Sistek-Chandler

Desiree Smith

Anchala Sobrin

Colleen Sologub-Sobering

Dr. Nicole Stephens

Lynn Thomas

Bren Vitter

Cinamon White

Kyriaki Xiraki-Tselios

Also, special thanks to our Digital Promise colleagues who assisted with co-designing our Edcamp: Design for Learning Series and led our educator panel discussions.

Kristal Brister Philyaw

Project Director, Learning Experience and Design Operations

Jessica Jackson

Practitioner Partnerships Director, Learner Variability Project

Dr. Stefani Pautz Stephenson

Director, Educator Community Partnerships

DeLisha Tapscott

Project Director, Operations \& Equity 